\title{
IMPAIRED EXERCISE RESPONSE AND OTHER RESIDUA OF PULMONARY STENOSIS AFTER VALVOTOMY
}

\author{
BY \\ A. M. JOHNSON \\ From the Cardiac Department, Guy's Hospital \\ Received February 18, 1962
}

The operation of pulmonary valvotomy has been so brilliantly successful that its failure to achieve an ideal end result in certain cases deserves comment. In this report, some residual effects of isolated pulmonary stenosis that may persist after complete valvotomy will be considered. It will be seen that all of these are the result of very severe stenosis or of long-delayed relief of stenosis of less severe degree. They constitute, therefore, a plea for early recognition of pulmonary stenosis and accurate assessment of its severity, so that operation, where needed, may not be unwarrantably delayed.

The conditions to be considered fall into two groups, each of which will be presented and discussed separately. Group I. Results of right ventricular myocardial fibrosis: (A) impaired response to exercise, and (B) persistence of reversed interatrial shunt.

Group II. Results of persistent right ventricular hypertrophy.

\section{GROUP I}

Right ventricular fibrosis is well recognized to occur as a result of severe pulmonary stenosis (Allanby and Campbell, 1949). Further, it has been shown that extensive myocardial fibrosis may produce hæmodynamic effects similar to those of chronic constrictive pericarditis (Hansen et al., 1951; Shillingford and Somers, 1961).

\section{(A). IMPAIRED EXERCISE RESPONSE}

Flow and pressure data were obtained in some patients with pulmonary stenosis and in others after pulmonary valvotomy, both at rest and during exercise. From each of these two sets of measurements, the pulmonary valve area was calculated by the formula of Gorlin and Gorlin (1951), in every case. Identity of the two results provided proof of the validity not only of the calculated valve area but also of the cardiac output estimation during exercise. It was found that exercise response was sometimes abnormal in the presence of pulmonary stenosis and also, in some cases, after stenosis had been relieved (Johnson, 1959a). The causes of impaired exercise response after pulmonary valvotomy were therefore studied. The findings are compared with those in patients unoperated upon and their significance is discussed.

Subjects and Methods. Thirteen patients with pulmonary stenosis, who had not had operation, and 17 who had been relieved by valvotomy were studied.

Cardiac catheterization, cardiac output estimation by the Fick method, and pressure measurements were carried out as previously described (Johnson, 1959a). Rest data were collected with the patient recumbent, in the fasting, basal state. Exercise measurements were made during the 
steady state achieved between the fifth and tenth minutes of pedalling, recumbent. The validity of the steady state at this time during exercise of the level performed by these subjects has been shown (Donald, 1959; Levy et al., 1961). Oxygen consumption at N.T.P. per square meter of body surface area was taken as the measure of work during exercise.

\section{Results}

The age at the time of investigation, the resting cardiac index, and resting right ventricular systolic pressure in patients unoperated upon and in those having had valvotomy are compared in Table I. It will be seen that the average age and resting cardiac index are the same in each group.

TABLE I

Comparison of Patients Investigated at Rest and Exercise in UnOPERATed and OPERATED GROUPS (MEANS AND RANGES)

\begin{tabular}{l|c|c}
\hline & Unoperated & Operated \\
\hline Age at time of investigation (years) & 19 & 18 \\
& $(6-45)$ & $(8-38)$ \\
Resting cardiac index (1./min./sq.m.) & $3 \cdot 3$ & $3 \cdot 5$ \\
& $(2 \cdot 1-5 \cdot 5)$ & $(1 \cdot 8-4 \cdot 7)$ \\
Resting R.V. syst. pressure (mm. Hg) & 101 & 58 \\
& $(65-193)$ & $(24-129)$ \\
\hline
\end{tabular}

By the criterion of resting right ventricular systolic pressure (Wood, 1956), the average severity of the unoperated group is "severe," while in the post-operative group it is in the "mild" to "moderate" zone.

In the electrocardiograms, right atrial and right ventricular hypertrophy were assessed. For right atrial hypertrophy, the amplitude of the $\mathrm{P}$ wave in lead II and the P/PR segment ratio (Macruz et al., 1958; Wyss et al., 1959), in the same lead were used. The mean values of these measurements were equal in the two groups (Table II), while right ventricular hypertrophy, judged by the criteria of Goodwin and Abdin (1959), was more severe in the unoperated group (Table III).

TABLE II

Cardiographic Evidence of Right Atrial Hypertrophy in Unoperated Cases and in Operated Cases Before aNd After Operation (Mean and Extreme Values)

\begin{tabular}{|c|c|c|c|c|}
\hline \multirow{3}{*}{\multicolumn{2}{|c|}{ Amplitude of $\mathbf{P}$ wave in II (mm.) }} & \multirow{3}{*}{$\begin{array}{c}\text { Unoperated } \\
\\
\begin{array}{c}1 \cdot 8 \\
(1 \cdot 0-3 \cdot 0)\end{array}\end{array}$} & \multicolumn{2}{|c|}{ Operated } \\
\hline & & & Pre-operative & $\begin{array}{l}\text { At post-operative } \\
\text { investigation }\end{array}$ \\
\hline & & & $\begin{array}{c}2 \cdot 6 \\
(1 \cdot 0-4 \cdot 5)\end{array}$ & $\begin{array}{c}1 \cdot 9 \\
(1 \cdot 0-4 \cdot 5)\end{array}$ \\
\hline P/PR segment ratio in II (Macruz et al., 1958) & .. & $\begin{array}{c}1 \cdot 0 \\
(0 \cdot 6-1 \cdot 2)\end{array}$ & $\begin{array}{c}1 \cdot 0 \\
(0 \cdot 6-1 \cdot 3)\end{array}$ & $\begin{array}{c}1 \cdot 0 \\
(0 \cdot 7-1 \cdot 5)\end{array}$ \\
\hline
\end{tabular}

Findings During Exercise. The cardiac index (1./min./sq.m.), plotted upon a graph published by Donald (1959), showed impairment of exercising cardiac output in 8 unoperated cases and in 7 after operation (Fig. 1). 
TABLE III

Degree of Right Ventricular Hypertrophy in Unoperated and in Operated Cases Before and After Operation

Number of cases unoperated

Operated, at time of operation

At post-operative investigation

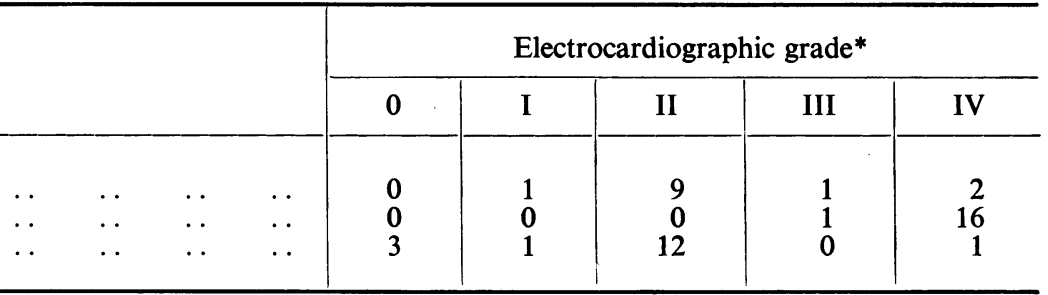

* Electrocardiographic criteria of Goodwin and Abdin, 1959.

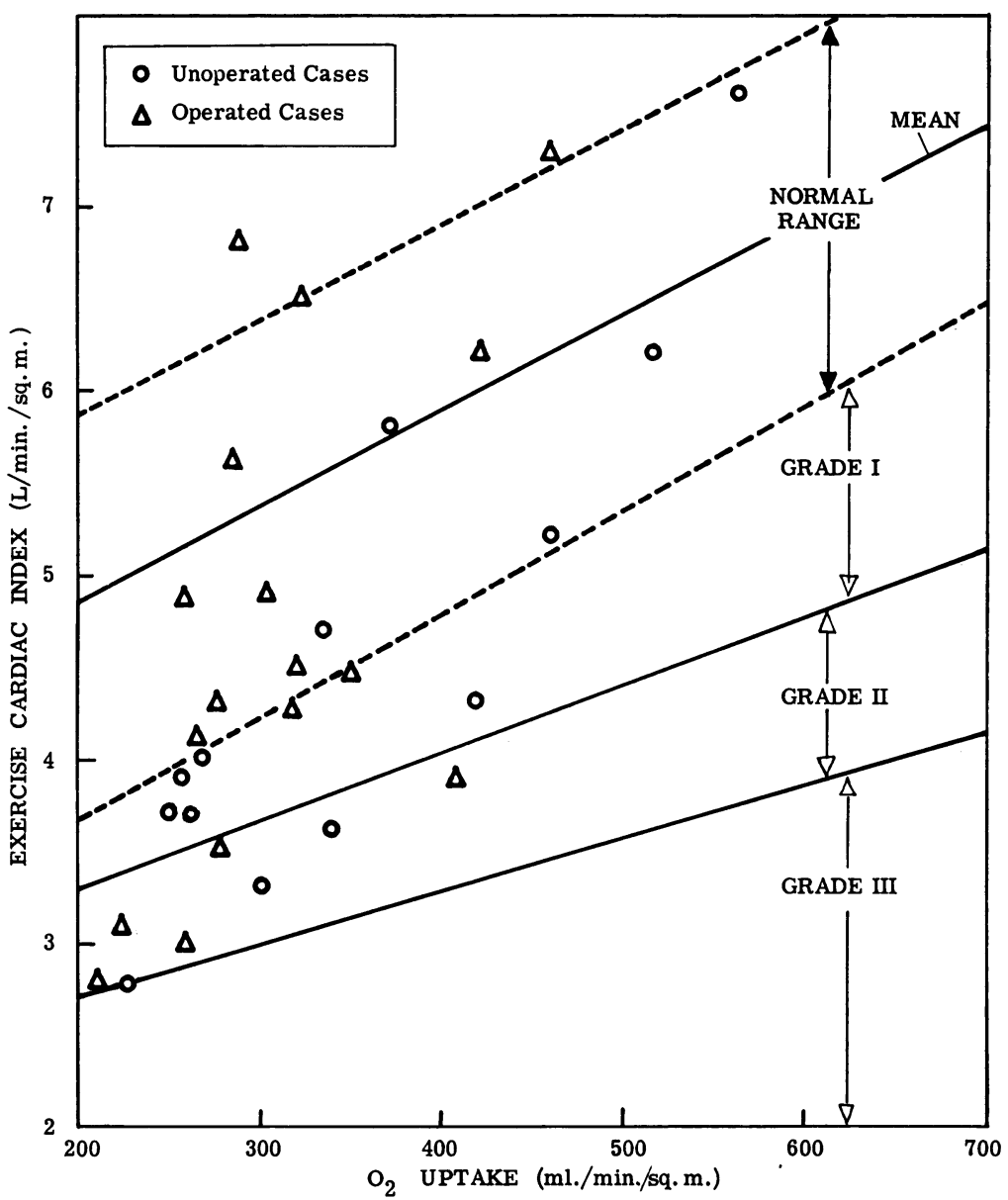

FIG. 1.-Cardiac output plotted against oxygen consumption as a measure of exercise, in unoperated and operated cases. (Normal regression line and three arbitrary grades of impairment from Donald, 1959.)

Arteriovenous oxygen difference increased beyond the limits of normality (Dexter et al., 1951) during exercise in 7 patients of each group. It had already been above the normal at rest in 2 unoperated and 4 operated patients (Fig. 2). This finding, of course, reflects impaired cardiac output in these patients. 


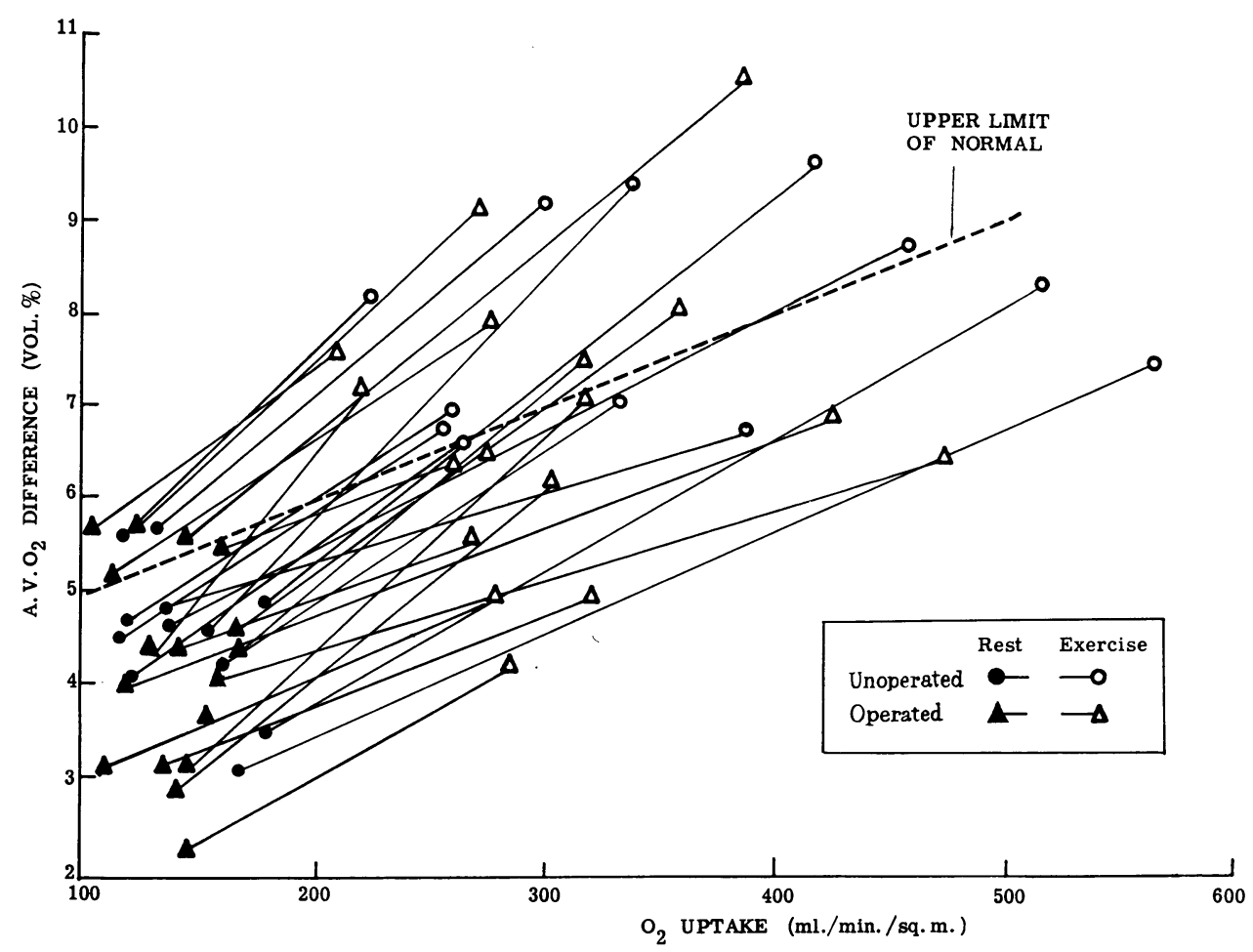

Fig. 2.-Arteriovenous oxygen difference at rest and during exercise in unoperated and operated cases. (Upper limit of normality from Dexter et al., 1951.)

Stroke Volume. Normally, stroke volume may be unchanged but usually rises on effort (Dexter et al., 1951; Freedman et al., 1955; Taylor and Donald, 1960). In the unoperated group it fell in 8 cases and the average was $41 \mathrm{ml}$. at rest, $37 \mathrm{ml}$. during exercise. Nine of the operated patients showed a fall, and average values were $45 \mathrm{ml}$. at rest and $42 \mathrm{ml}$. during exercise.

Heart Rate. In the presence of an unchanged or reduced stroke volume, increase of cardiac output was achieved by tachycardia in excess of normal for the amount of work performed. At rest, in the unoperated group, mean oxygen consumption was $145 \mathrm{ml} . / \mathrm{min} . / \mathrm{sq} . \mathrm{m}$. , and the mean heart rate 83 a minute; and in the operated group, mean oxygen consumption was $139 \mathrm{ml} . / \mathrm{min} . / \mathrm{sq} . \mathrm{m}$. and the mean heart rate 81 a minute. These figures are identical with those of normal subjects reported by Taylor and Donald (1960).

During exercise, in the unoperated patients, mean oxygen consumption was $355 \mathrm{ml} . / \mathrm{min} . / \mathrm{sq} . \mathrm{m}$. with a mean heart rate 127 a minute; and in the operated cases, mean oxygen consumption of 314 ml./min./sq.m. was associated with a mean heart rate of 114 a minute. The normal subjects of Taylor and Donald (1960) showed a similar heart rate for twice the amount of work.

Systolic ejection period, measured from superimposed pulmonary arterial and right ventricular pressure records, was shortened in each cycle as normally and, by virtue of tachycardia, increased each minute.

The increased proportion of the cardiac cycle occupied by systolic ejection from the right ventricle during exercise may be seen from the ratio of systolic ejection period (seconds per cycle) and cycle length (seconds). In the unoperated group, this ratio was 0.48 at rest and 0.55 during exercise; and in the operated group it was 0.40 at rest and 0.48 during exercise. The effect of pulmonary valvotomy in lowering this ratio is also shown. 
Right Ventricular Systolic Pressure. In the presence of pulmonary stenosis, and in the absence of right ventricular failure, the degree of rise of right ventricular systolic pressure during exercise depends upon two factors. One of these is the shortening of the systolic ejection period per cycle which results from tachycardia and tends to increase it. The other is the stroke volume, which depends upon the adequacy of right ventricular filling during diastole. As already shown the relative shortening of diastole with tachycardia results, in these cases, in a fall of stroke volume during exercise, even though the filling pressure increases (Fig. 3). It was the fall of stroke volume

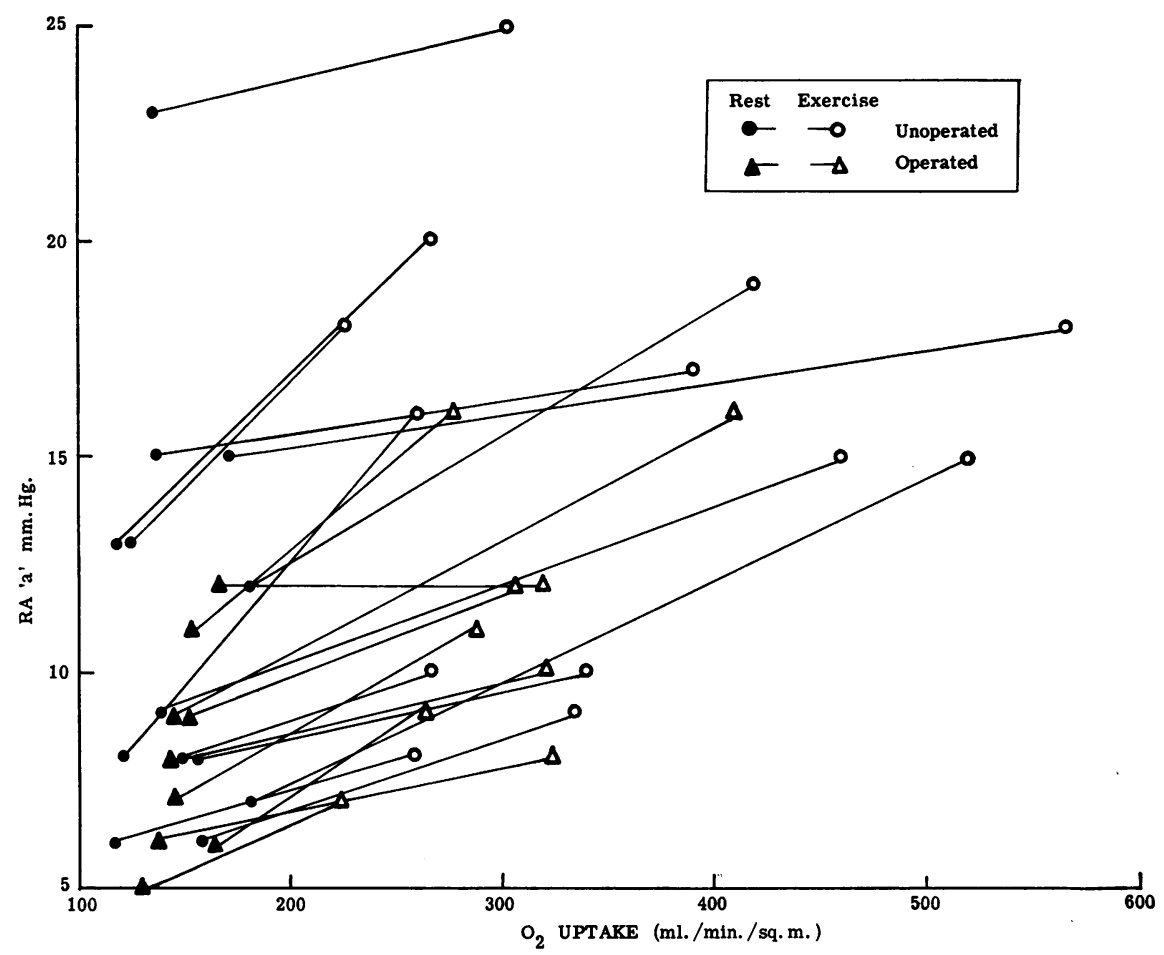

FIG. 3.-Right atrial $a$ wave at rest and during exercise. It is used here as an index of right ventricular filling pressure, small changes being more easily measured during exercise than those of right atrial mean pressure.

in some of these cases that first suggested that increased filling resistance of the right ventricle might be the factor limiting filling in diastole. If stroke volume falls, right ventricular systolic pressure will tend to fall with it and, conversely, increased stroke volume will cause a rise in the right ventricular systolic pressure.

As would be expected, therefore, no general rule can be stated regarding the degree of rise of right ventricular systolic pressure during exercise. Though it is true that some cases in the range of moderate severity roughly doubled their systolic pressure on exercise (Campbell, 1960), not all cases did so (Fig. 4).

\section{Discussion}

In the presence of pulmonary stenosis, the large increase of right ventricular systolic pressure observed in the beat following the compensatory pause after a premature beat indicates the ability of the right ventricle to increase its pressure in response to increased filling during a longer diastole 
(Fig. 5). This denies the suggestion (Fabricius, 1959), that impaired cardiac output during exercise in such cases is due to inability of the right ventricle to increase its pressure sufficiently. Rather, it is suggested, prolonged ejection causes relative shortening of diastole which, in the presence of increased resistance to filling on the part of the ventricle itself, impairs filling, reduces stroke volume, and so keeps down the right ventricular systolic pressure.

Impaired response of cardiac output to exercise is thus due to $(a)$ prolonged right ventricular ejection, causing shortening of diastolic filling time, and $(b)$ increased right ventricular filling resistance, due to right ventricular hypertrophy. In severe cases, myocardial fibrosis is known to develop and constitutes an additional cause of increased resistance to ventricular filling.

Shortening of the systolic ejection period per minute following valvotomy (Fig. 6) reflects diminished resistance to right ventricular emptying. Nevertheless, the response to exercise may still be abnormal after operation. The fundamental defect now seems to be impaired right ventricular filling, despite the larger proportion of the cardiac cycle occupied by diastole. Stroke volume is thus smaller than normal and even excessive tachycardia may fail to compensate for this. It is suggested that this may be accounted for by the persistence of increased right ventricular filling resistance, due to myocardial fibrosis, even when ventricular hypertrophy has resolved. The pattern associated with chronic constrictive pericarditis or myocardial fibrosis (Hansen et al., 1951) and endomyocardial fibrosis (Shillingford and Somers, 1961) may be seen in the right atrial and right ventricular pressure waves in cases after operation that show impairment of exercising cardiac output (Fig. 7). The $\mathrm{T}$ wave abnormalities that sometimes persist after pulmonary valvotomy may also reflect this. 


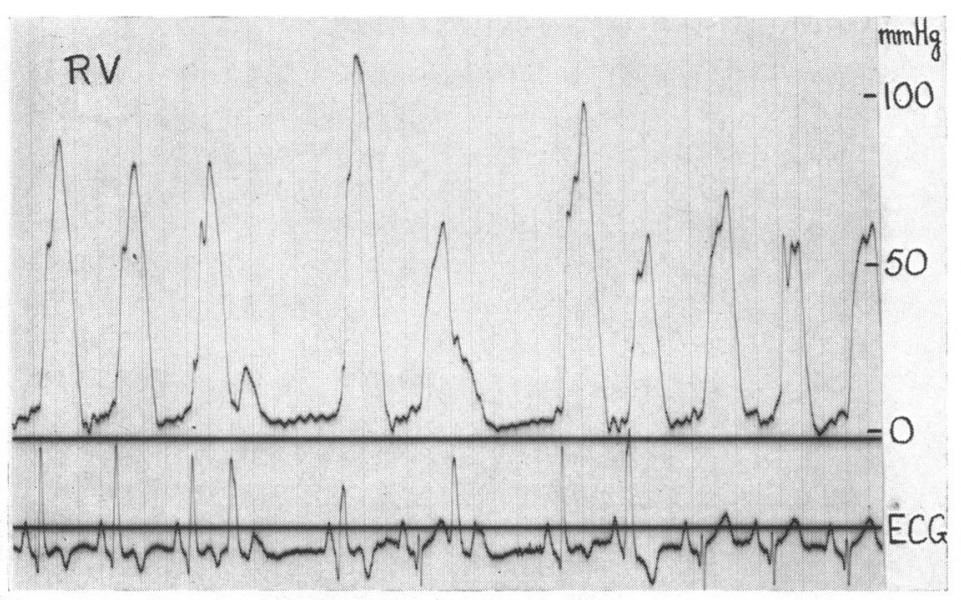

Fig. 5.-The effect of longer and shorter diastoles upon right ventricular systolic pressure, in the presence of pulmonary stenosis. Variations are due to changing ventricular filling, related to varying length of diastole. The arrhythmia was caused by the presence of the catheter in the right ventricle.

FIG. 6.-Shortening of systolic ejection period (sec./min.) following pulmonary valvotomy. In 5 cases there was no pre-operative measurement.
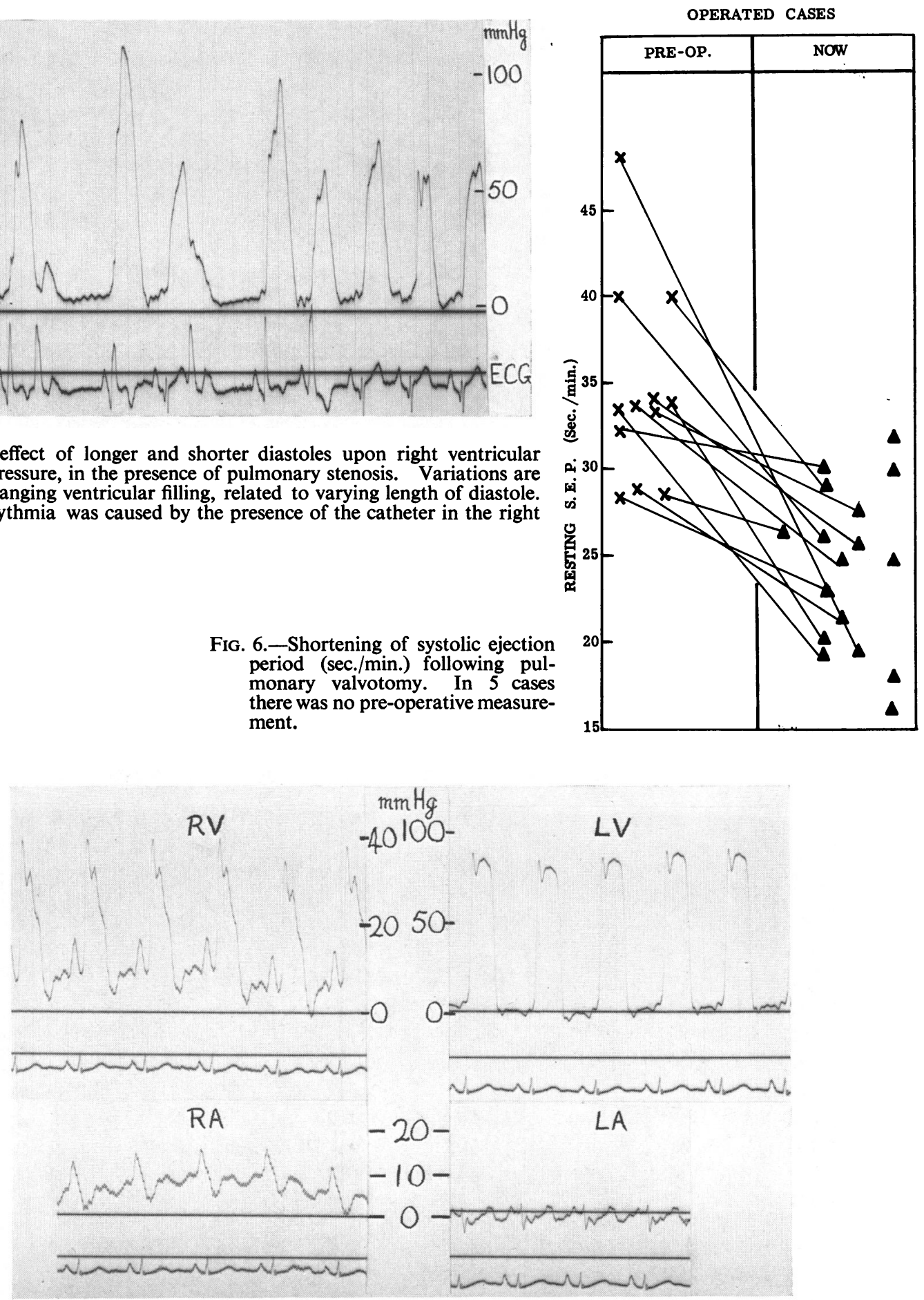

FIG. 7.-Case 2. Pressure records, during the resting state, from both atria and ventricles, at catheterization seven years after pulmonary valvotomy. The R.A. and R.V. records show the "constriction pattern," in contrast with the normal pattern in L.A. and L.V. 


\section{(B). Persistence of Reversed Interatrial Shunt}

Brock (1961) has already drawn attention to the importance of closing any interatrial communication at the time of pulmonary valvotomy, in cases of severe isolated pulmonary stenosis with central cyanosis due to reversed interatrial shunting. He reported two patients in whom severe central cyanosis persisted after pulmonary valvotomy, for eight years in one and for seven years in the other, in spite of regression of right ventricular hypertrophy, complete in the one and almost complete in the other. Right ventricular systolic pressure had been reduced to normal in both, as was proved by cardiac catheterization. "Diminished diastolic filling power of the right ventricle" was postulated as the cause of the continued right to left interatrial shunt, and it will be worth while, in the present context, to add to his descriptions of these two cases the positive evidence that this was in fact the mechanism.

Case 1. A.F., a man aged 23 at the time of valvotomy for severe pulmonary stenosis and 31 when he had his second operation for closure of a valve-patent foramen ovale, showed a jugular $a$ wave dominant but not pathological at rest but increasing to $4 \mathrm{~cm}$. above sternal angle level on mild exercise. Auscultation revealed a loud atrial sound. The cardiogram still showed evidence of right atrial hypertrophy, in a P/PR-segment ratio of 1.0 in lead II and sharply pointed $1.5 \mathrm{~mm}$. right atrial component of the $\mathrm{P}$ wave in lead V1. There was no longer any evidence of right ventricular hypertrophy.

Case 2. A.C., a girl in whom pulmonary valvotomy was performed at the age of 5 for severe pulmonary stenosis, is now aged 12. She shows a giant jugular venous $a$ wave and has a right ventricular third sound. The cardiogram (Fig. 8) shows grade 1 right ventricular hypertrophy compared with grade 4 before operation,

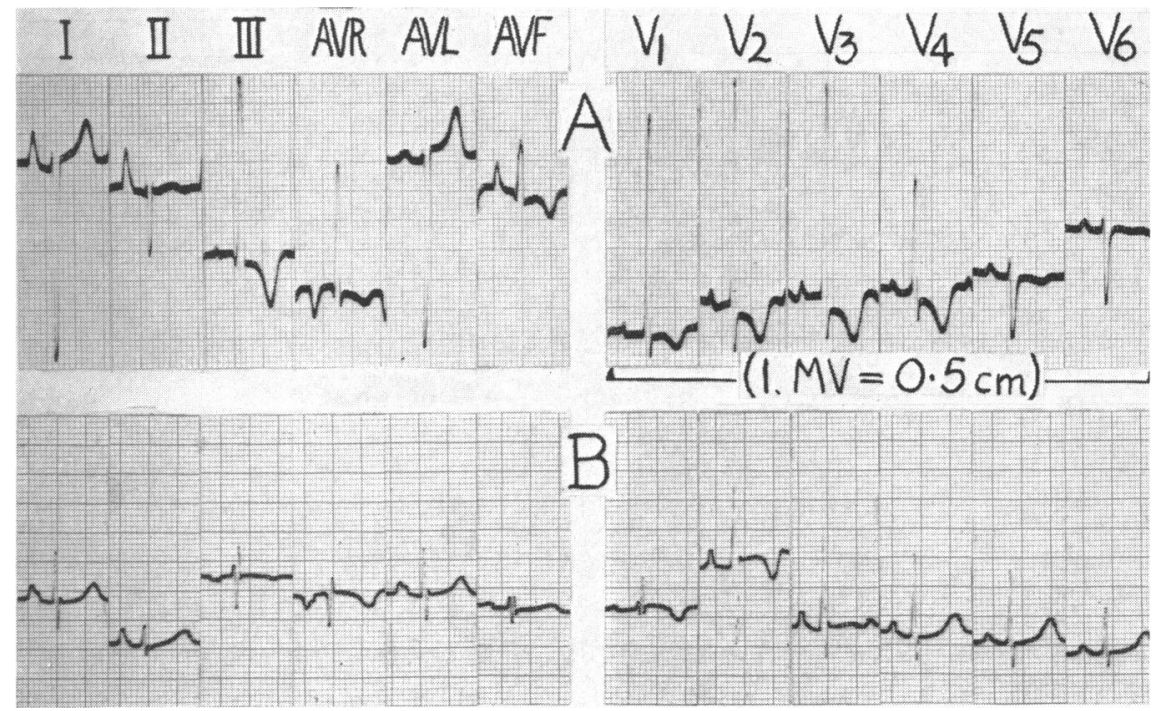

FIG. 8.-Case 2. Electrocardiograms, at time of pulmonary valvotomy, aged 5 (A) and seven years later $(B)$.

but the $\mathbf{P}$ wave still shows evidence of right atrial hypertrophy. The right ventricular pressure records now show the constriction pattern (Hansen et al., 1951), contrasting with the normal patterns in left atrium and left ventricle obtained at the same time (Fig. 7).

Since these two cases were described (Brock, 1961), a third patient has been seen who shows the same phenomenon and merits brief description.

Case 3. A girl, J.G., was aged 8 when first seen by Dr. Campbell, with a history of cyanosis and dyspnœa since a few weeks old. She had never squatted. Isolated pulmonary stenosis and Fallot's tetralogy formed the differential diagnosis and in January, 1950, she was sent to Mr. Holmes Sellors with the latter diagnosis. He performed a left Blalock operation and noted appearances of pulmonary valve stenosis. After this, she 
had improved effort tolerance but was still variably cyanosed. Subsequently she was observed by Dr. Somerville who, in 1954, noted worsening of dyspnœa and cyanosis. The anastomotic murmur was no longer audible. Venous angiocardiography showed early aortic filling, though whether the right-to-left shunt responsible for this occurred at atrial or ventricular level could not be defined. The pulmonary stenosis was seen to be valvar. In November, 1954, Mr. Holmes Sellors carried out closed pulmonary valvotomy. Hypertrophic infundibular stenosis supervened at once, so that the gradient between right ventricle and pulmonary artery was not adequately relieved. Infundibular punch resection was therefore performed. A year later there was great improvement in effort tolerance though some cyanosis was still present. The pulmonary systolic murmur was now "very slight" and by 1956 it had "practically disappeared." In May, 1959, she was seen again at Guy's Hospital. Examination now showed marked central cyanosis and digital clubbing. At rest there was a jugular venous $a$ wave $6 \mathrm{~cm}$. above sternal angle level, with rapid and deep $x$ and $y$ descents visible. The cardiac impulse was normal. Auscultation revealed a normal first sound, no systolic murmur, a normal second sound with pulmonary component of normal intensity, a loud right ventricular third sound, and a moderately loud atrial sound. There was no diastolic murmur. The cardiogram (Fig. 9), which had originally shown severe right ventricular hypertrophy, was now normal.

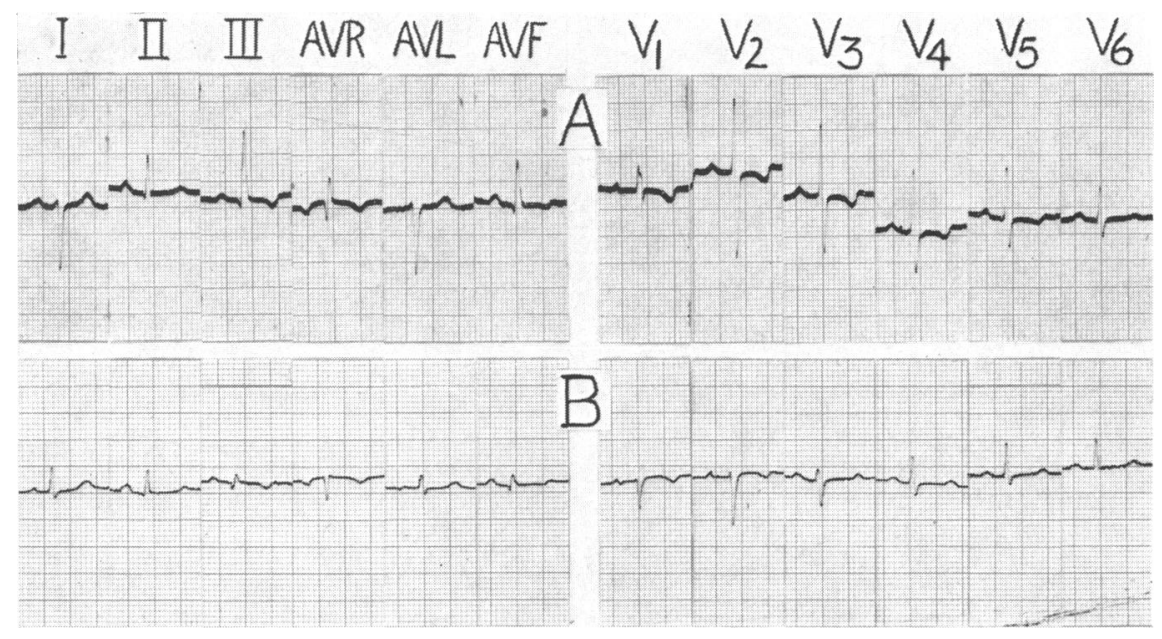

Fig. 9.-Case 3. Electrocardiograms, one year after Blalock operation, aged 13 (A), and five years after pulmonary valvotomy, aged 21 (B).

The course of events has thus shown that this was a case of severe pulmonary valve stenosis with reversed interatrial shunt. Pulmonary valvotomy was complete and severe right ventricular hypertrophy, responsible for functional infundibular stenosis which was partially relieved by infundibular resection, has subsequently regressed completely. Reversed interatrial shunt, however, persists and the large jugular venous $a$ waves and atrial sound provide evidence of increased right ventricular filling resistance. The deep $x$ and $y$ descents also noted clinically, suggest that the pattern of "constriction" is present.

\section{Discussion}

These three cases illustrate a further effect of right ventricular myocardial fibrosis with increased ventricular filling resistance. The importance of closing any interatrial communication, even a valve-patent foramen ovale, at the time of valvotomy in cyanosed patients with severe pulmonary stenosis, as stressed by Brock (1961), is clear. The ill-effects of central cyanosis will thereby be relieved, though the myocardial fibrosis presumably cannot be influenced and right atrial work will continue to be increased. The response of the heart to exercise will remain abnormal and, ultimately, right ventricular failure may be expected to occur. 


\section{Group II. Persistent Right Ventricular Hypertrophy}

It is now well recognized that right ventricular outflow obstruction results from severe right ventricular hypertrophy and that this occurs as a complication of severe pulmonary valve stenosis. It is also known that, after pulmonary valvotomy, such hypertrophic infundibular stenosis usually regresses completely within a year or so. Brock (1961) has recently stated that such a course of events is the rule and that resection of infundibular muscle after pulmonary valvotomy, even when right ventricular systolic pressure remains very high, is not necessary. He showed that it may, in fact, be ineffective in achieving a further lowering of right ventricular pressure in these circumstances. The proposition that a residual right ventricular systolic pressure in excess of $100 \mathrm{~mm}$. $\mathrm{Hg}$ after valvotomy should be considered as an indication for infundibular muscle resection (Johnson, 1959a) was refuted. Two cases reported here, however, show that persistently high right ventricular pressure may greatly impede regression of right ventricular hypertrophy, as previously noted (Johnson, 1959a), so that, despite complete valvotomy, the right ventricle is not adequately relieved of its burden at least over several succeeding years.

Case 4. L.K., a girl, aged 14, at the time of open pulmonary valvotomy by Mr. Donald Ross for severe isolated pulmonary stenosis. There was no pre-operative cardiac catheterization, but pressures measured at operation, before and after valvotomy, showed that severe valve stenosis was completely relieved only to be replaced by equally severe functional infundibular stenosis (Table IV). A finger was passed down into

TABLE IV

Pressure Data in Two Cases of Persistent Hypertrophic Infundibular Stenosis (mm. Hg)

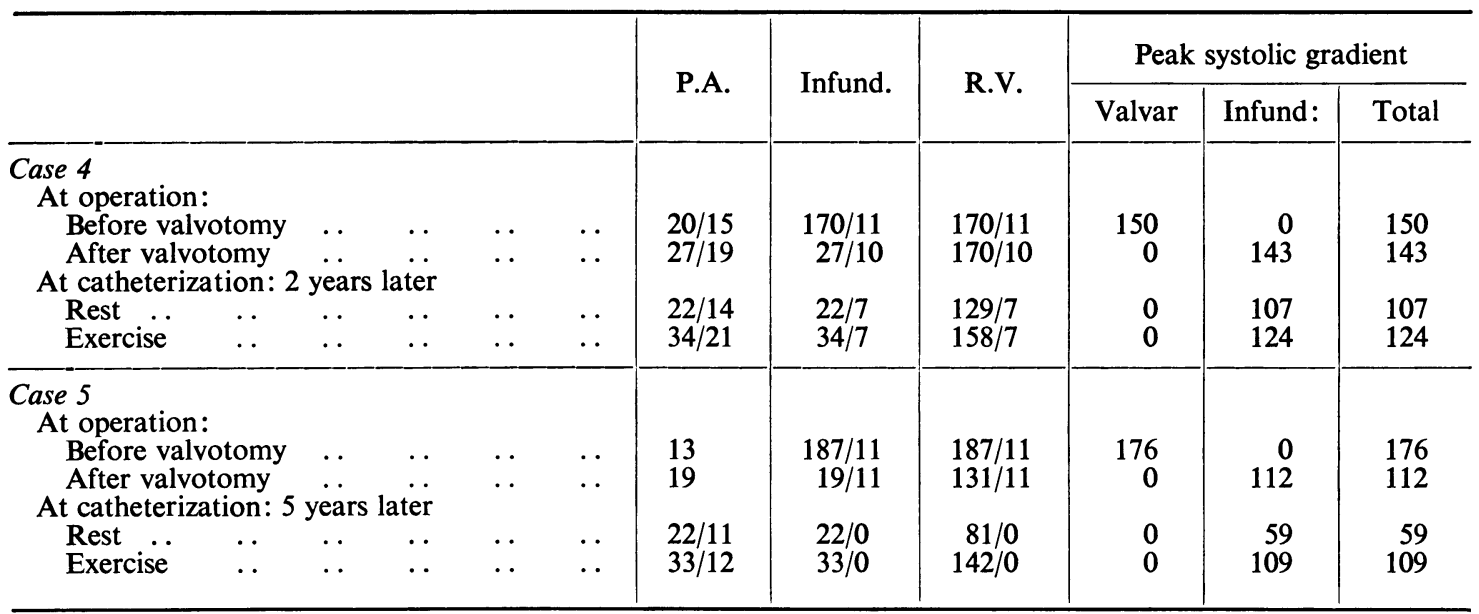

the right ventricle, where powerful contraction of the outflow tract was noted but organic obstruction was excluded. No infundibular resection was carried out. Post-operatively, congestive heart failure occurred and required full medical treatment. One month after operation, a phonocardiogram showed a grossly delayed and soft pulmonary component of the second sound $(0.12 \mathrm{sec}$. after the aortic component). The pulmonary systolic murmur, however, no longer overlapped the aortic component. These are the auscultatory features of severe hypertrophic infundibular stenosis (Johnson, 1959b), and they persisted to the time of recatheterization two years after operation. At this investigation, severe functional infundibular stenosis was shown still to be present (Table IV). The cardiogram showed persistence of severe right ventricular hypertrophy, though it was a little less gross than before operation (Fig. 10). Chest X-rays showed right atrial and right ventricular enlargement as before operation, with cardiothoracic ratio $15 / 26 \mathrm{~cm}$. compared with $14 \cdot 5 / 25 \mathrm{~cm}$. before operation.

Case 5. J.T., a girl aged $5 \frac{1}{2}$ when she was first seen with the signs of severe isolated pulmonary valve stenosis. At open valvotomy 3 months later, by Sir Russell Brock, right ventricular systolic pressure was reduced from 187 to $131 \mathrm{~mm}$. $\mathrm{Hg}$, the valve stenosis being completely abolished, to be replaced by hypertrophic infundibular stenosis (Table IV). For one month after operation she was in congestive heart failure, but thereafter made a good recovery. Five years later she still showed a giant $a$ wave in the neck veins, a loud 


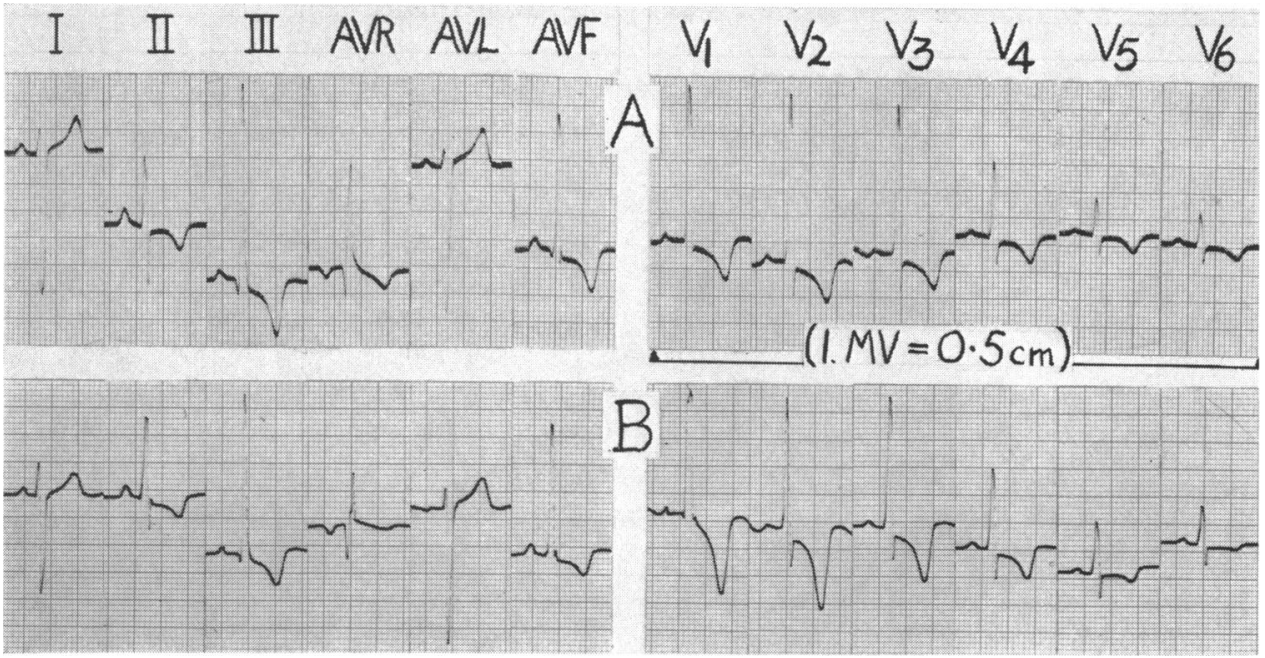

Fig. 10.-Case 4. Electrocardiograms, at time of pulmonary valvotomy, aged 14 (A), and two years later (B).

pulmonary systolic murmur almost reaching the aortic component of the second sound, and a very delayed and faint pulmonary component. Catheterization showed severe functional infundibular stenosis still to be present (Table IV). In the cardiogram (Fig. 11), some right ventricular hypertrophy was still evident. Chest X-ray showed persistence of right atrial and right ventricular enlargement, with cardiothoracic ratio $11 \cdot 5 / 22 \mathrm{~cm}$. compared with $11 / 19 \cdot 5 \mathrm{~cm}$. before operation.

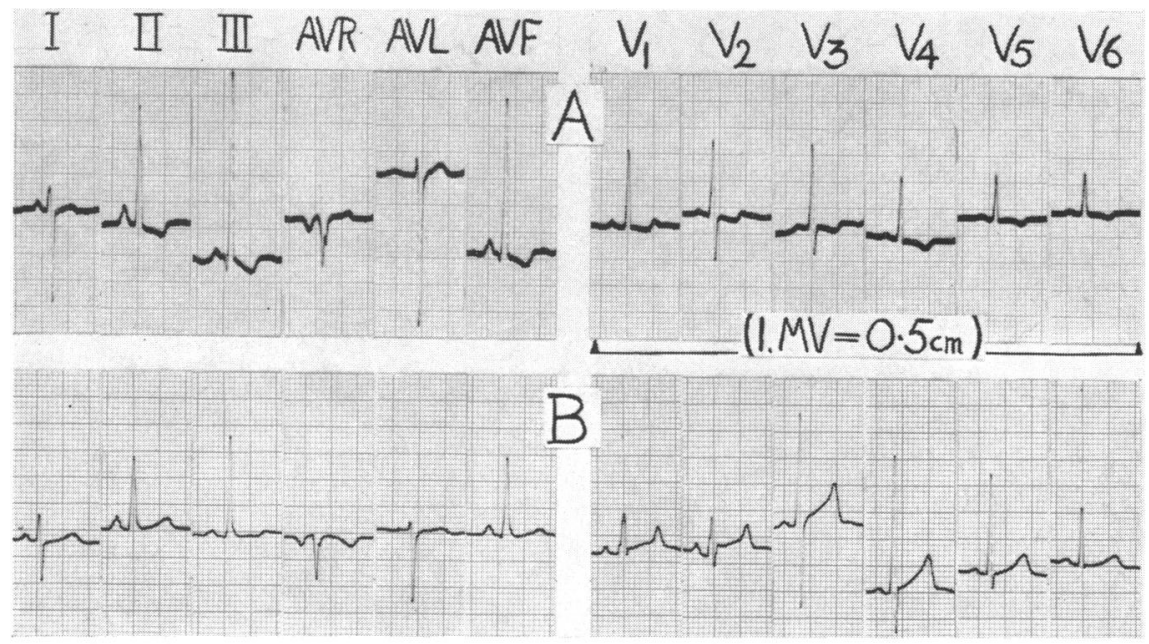

Fig. 11.-Case 5. Electrocardiograms, at time of pulmonary valvotomy aged $5(\mathrm{~A})$, and five years later $(B)$.

\section{Discussion}

These two patients, showing persistence of severe functional infundibular stenosis for two and five years respectively after complete open pulmonary valvotomy, seem to support the suggestion that severe right ventricular hypertension after valvotomy is an indication for infundibular muscle resection. Using the criterion of a persistent right ventricular systolic pressure of $100 \mathrm{~mm}$. $\mathrm{Hg}$ or 
more after valvotomy, Kirklin (1961) has successfully followed this practise: his aim has been to reduce right ventricular systolic pressure so that it does not exceed 75 per cent of the systemic figure. The lowering, or further lowering, of right ventricular pressure by this means allows right ventricular hypertrophy to regress, so that the milder degree of associated functional infundibular stenosis proceeds spontaneously to complete resolution. Clearly, the continued presence of such severe right ventricular hypertension as occurred in these two cases invites development or progression of right ventricular myocardial fibrosis, even after complete valvotomy, with the consequences described in the previous sections of this paper.

It is seen from the facts presented here that the cardiac surgeon, while he may achieve success in the relief of pulmonary valve stenosis, may yet be denied commensurate physiological success in two ways. Both result from the severity and duration of the lesion he has corrected.

In the first place, severe right ventricular hypertrophy may result in development of severe functional infundibular stenosis immediately the valve stenosis is relieved. If he has succeeded in lowering right ventricular systolic pressure below about $100 \mathrm{~mm}$. $\mathrm{Hg}$, regression of right ventricular hypertrophy over the succeeding months will complete his task of restoring the right ventricular load to normality. If, however, severe functional infundibular stenosis has maintained right ventricular systolic pressure above $100 \mathrm{~mm}$. $\mathrm{Hg}$, its regression may be slow (Hosier et al., 1956; Johnson, 1959a), or, as shown in the present report, may virtually fail to occur over a period of up to five years. Thus, the conditions that lead to right ventricular myocardial fibrosis may persist for a long time after valvotomy.

We have shown that, even after complete relief of right ventricular obstruction and complete regression of right ventricular hypertrophy, disturbed function of the right ventricle may be mani-

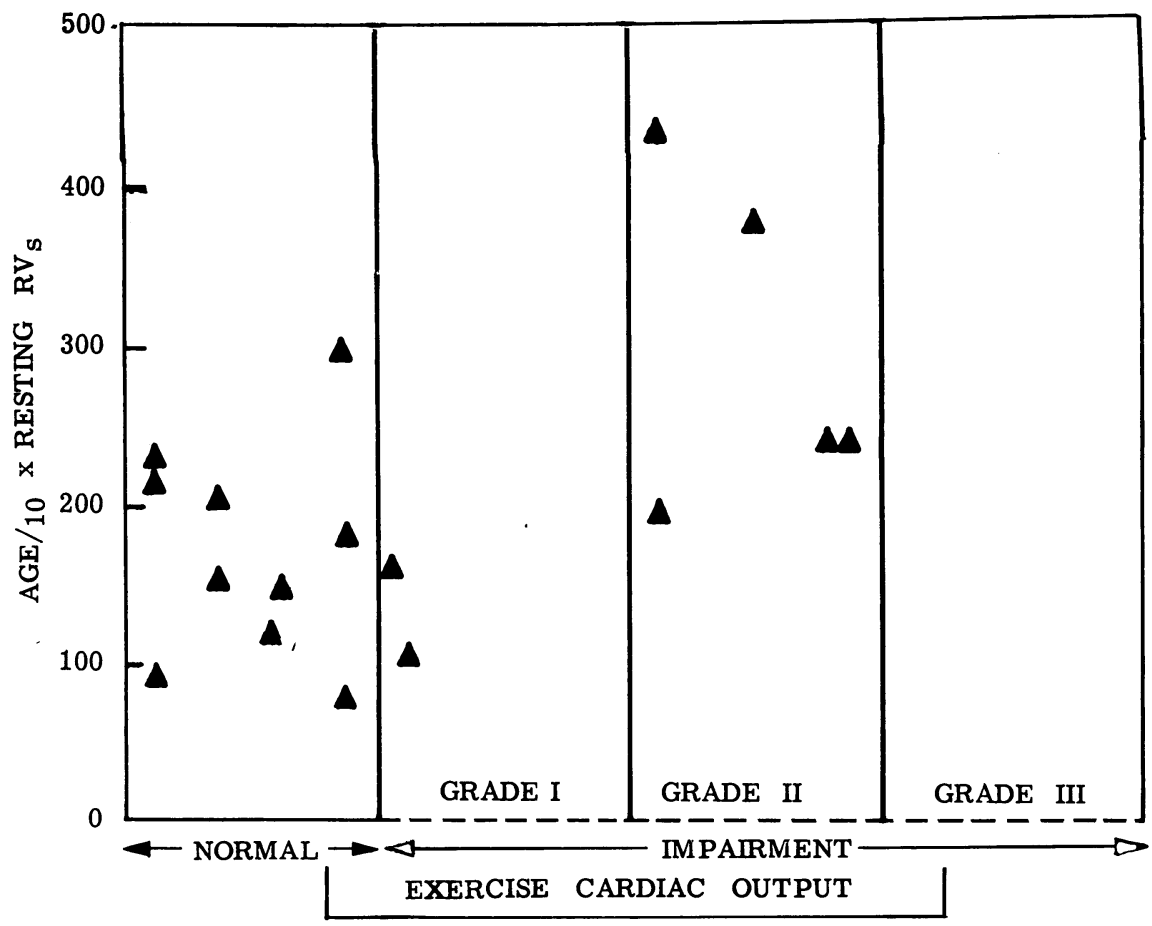

FIG. 12.-The product of age in decades and resting RV systolic pressure, at time of operation in the 17 operated cases (an expression combining duration and severity of pulmonary stenosis), plotted against the normality or grade of impairment of exercising cardiac output (Donald, 1959) at time of post-operative investigation. 
fested by hæmodynamic abnormalities including impaired response of cardiac output to exercise. That both the severity of the pulmonary stenosis and its duration are important in determining this permanent physiological defect is indicated by the direct correlation between the degree of impairment of cardiac output increase during exercise and the product of resting right ventricular systolic pressure and age at operation (Fig. 12). Neither right ventricular systolic pressure nor age alone shows any correlation but it is evident that severity of stenosis plays a more important part than duration in the production of permanent myocardial damage. Thus, severe stenosis will produce irreversible changes early, moderate stenosis may not do so until middle life, and mild stenosis may never do so. The importance of providing sufficient relief for the right ventricle as soon as possible is thus evident and, if infundibular muscle resection in addition to valvotomy is necessary to achieve this, it seems justifiable to undertake the extra surgical step, the efficacy and safety of which has been proved by Kirklin (1961). The shortcomings of a single figure that shall be taken to indicate the need for muscle resection after valvotomy are, of course, admitted. Nevertheless, this figure is based upon observations of mortality and morbidity after operation (Johnson, 1959a) and, in the operating theatre, a reasonably established and relatively simple criterion may be of great practical value in making an otherwise difficult decision.

\section{SUMMARY}

A hæmodynamic study of 13 patients with pulmonary stenosis and of 17 patients subjected to valvotomy is reported. Impaired exercise response was found in both groups. In the presence of pulmonary stenosis, relative shortening of diastole due to prolonged right ventricular ejection, combined with increased right ventricular filling resistance, appear to be the factors limiting cardiac output increase during exercise. After operation, the factor of increased filling resistance alone may suffice to cause persistence of an abnormal response to effort.

The same mechanism appears to be responsible for the occasional continuation of reversed interatrial shunting after valvotomy for severe pulmonary stenosis.

Myocardial fibrosis seems to be the cause of increased right ventricular filling resistance, even after complete resolution of hypertrophy.

Perpetuation of hypertrophic infundibular stenosis by high residual right ventricular systolic pressure after valvotomy is illustrated by case reports and the importance of the duration and severity of right ventricular hypertension in relation to the production of myocardial fibrosis is stressed. Early and adequate relief of severe right ventricular hypertension is urged, and the question of infundibular muscle resection after pulmonary valvotomy is discussed again in the light of these findings.

The unfailing interest of Sir Russell Brock in this work and the helpful criticism of Dr. C. G. Baker in the preparation of this paper are gratefully acknowledged.

My thanks are due to them and to Dr. D. C. Deuchar for permission to study and report these cases; to Dr. Paul Wood, with whose permission four of the patients unoperated upon were studied, during tenure of a post at the Institute of Cardiology; and to Dr. Walter Somerville for providing details of Case 3 while she was under the care of himself and Mr. Holmes Sellors.

\section{REFERENCES}

Allanby, K. D., and Campbell, M. (1949). Guy's Hosp. Rep., 98, 18.

Brock, R. C. (1961). Brit. Heart J., $23,337$.

Campbell, M. (1960). Brit. Heart J., 22, 101.

Dexter, L., Whittenberger, J. L., Haynes, F. W., Goodale, W. T., Gorlin, R., and Sawyer, C. G. (1951). J. appl. Physiol., 3, 439.

Donald, K. W. (1959). Brit. med. J., 1, 985.

Fabricius, J. (1959). Isolated Pulmonary Stenosis. Munksgaard, Copenhagen.

Freedman, M. E., Snider, G. L., Brostoff, P., Kimelblot, S., and Katz, L. N. (1955). J. appl. Physiol., 8, 37.

Goodwin, J. F., and Abdin, Z. H. (1959). Brit. Heart J., 21, 523.

Gorlin, R., and Gorlin, S. G. (1951). Amer. Heart J., 41, 1.

Hansen, A. T., Eskilden, P., and Gotzsche, H. (1951). Circulation, 3, 881.

Hosier, D. M., Pitts, J. L., and Taussig, H. B. (1956). Circulation, 14, 9. 
Johnson, A. M. (1959a). Brit. Heart J., 21, 429.

(1959b). Guy's Hosp. Rep., 108, 373.

Kirklin, J. W. (1961). Personal communication.

Levy, A. M., Tabakin, B. S., and Hanson, J. S. (1961). Brit. Heart J., 23, 425.

Macruz, R., Perloff, J. K., and Case, R. B. (1958). Circulation, 17, 882.

Shillingford, J. P., and Somers, K. (1961). Brit. Heart J., 23, 433.

Taylor, S. H., and Donald, K. W. (1960). Brit. Heart J., 22, 117.

Wood, P. H. (1956). Diseases of the Heart and Circulation, 2nd. ed. Eyre and Spottiswoode, London.

Wyss, S., Schaub, F., and Bühlmann, A. (1959). Cardiologia, 35, 279. 